\title{
Which is Superior, Doppler Velocimetry or Non-stress Test or Both in Predicting the Perinatal Outcome of High-Risk Pregnancies
}

\author{
Vijaya Subramanian $^{1} \cdot$ Janani Venkat $^{1} \cdot$ Mohana Dhanapal $^{1}$
}

Received: 19 June 2015/Accepted: 23 November 2015/Published online: 2 February 2016

(C) Federation of Obstetric \& Gynecological Societies of India 2016

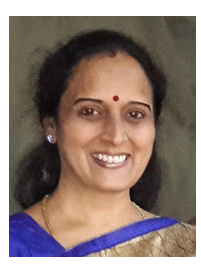

\begin{abstract}
About the Author
Dr. S. Vijaya MD DGO working as Professor of Obstetric and Gynaecology at the Institute of Social Obstetrics and Government Kasturba Gandhi Hospital attached to Madras Medical College, Chennai. She has been a undergraduate and postgraduate examiner in Tamil Nadu, Kerala and Karnataka. She has more than 20 years of teaching experience and executive committee member of OGSSI. She has presented paper in national conference. Her field of interest is operative laparoscopy and social obstetrics.
\end{abstract}

\begin{abstract}
Aim and Objectives To analyze which is superior, Doppler velocimetry or non-stress test or both by means of categorization into four groups and comparing the prediction of perinatal outcome in high-risk pregnancies like anemia, hypertensive disorders of pregnancies.

Materials and Methods This was a prospective study conducted at the Department of Obstetrics and
\end{abstract}

Vijaya Subramanian is Professor in the Institute of Social Obstetrics, Kasturba Gandhi Hospital; Janani Venkat is Doctor in the Institute of Social Obstetrics, Kasturba Gandhi Hospital; Mohana Dhanapal is Doctor in the Institute of Social Obstetrics, Kasturba Gandhi Hospital.

Janani Venkat jananivenkat1988@gmail.com

1 Institute of Social Obstetrics, Kasturba Gandhi Hospital, Triplicane, Chennai 600005, India
Gynaecology, ISO KGH, Madras Medical College, Chennai, in the year 2014. Two hundred high-risk pregnancies like anemia, hypertensive disorders of pregnancy were included in the study. They were examined systematically, and Doppler velocimetry and non-stress test were done. The main vessels studied by Doppler were umbilical artery and middle cerebral artery, and the indices were calculated. The results of the non-stress test were interpreted as reactive and non-reactive. Based on the results of Doppler and non-stress test, the 200 cases were categorized into four groups and the results were analyzed.

Results Among the 200 cases of high-risk pregnancies, those with a normal Doppler study and a reactive nonstress test had good perinatal outcome. When both were abnormal, there was a higher percentage of adverse outcome as compared to that of either Doppler alone being abnormal or non-stress test alone being non-reactive. It was 
also found that abnormal Doppler but with a reactive nonstress test had the advantage of prolonging the pregnancy and bringing a better outcome indicating that non-stress test is surely a good test of well-being. When Doppler was normal, but non-stress test was non-reactive, there was an increase in the rate of cesarean section.

Conclusion Each method of fetal surveillance reflects different aspect of maternal and fetal pathophysiology. Hence, combining these will help to bring out better perinatal outcome.

Keywords Doppler velocimetry $\cdot$ Non-stress test . High-risk pregnancy $\cdot$ Perinatal

$\begin{array}{ll}\text { Abbreviation } & \\ \text { NST } & \text { Non-stress test } \\ \text { PSV } & \text { Peak systolic velocity } \\ \text { MCA } & \text { Middle cerebral artery } \\ \text { UA } & \text { Umbilical artery } \\ \text { EDV } & \text { End diastolic velocity } \\ \text { IUGR } & \text { Intrauterine growth retardation } \\ \text { S/D ratio } & \text { Systolic-to-diastolic ratio } \\ \text { APLA } & \text { Antiphospholipid antibody syndrome } \\ \text { NICU } & \text { Neonatal intensive care unit } \\ \text { GAD } & \text { Gestational age at delivery } \\ \text { GDM } & \text { Gestational diabetes mellitus } \\ \text { Mode of del } & \text { Mode of delivery } \\ \text { Birth wt } & \text { Birth weight } \\ \text { CPR } & \text { Cerebro-placental ratio }\end{array}$

\section{Introduction}

Fetal surveillance is performed to identify the "at-risk" fetuses correctly, and a timed intervention is more useful in cases of high-risk pregnancies.

Complete knowledge about the disease and some intervention possible at the correct time can prevent mortality and morbidity. The recent trend is to combine the modalities of fetal surveillance like biophysical profile, Doppler to monitor the fetuses.

\section{Doppler Velocimetry $[1,2]$}

\section{Doppler Effect}

When the reflector or the target is moving, there is a shift in the frequency of the reflected echoes.

\section{Doppler Detects}

1. The presence or absence of flow,
2. Flow direction,

3. Flow characteristics.

\section{Doppler Indices}

1. S-peak systolic velocity,

2. D—end diastolic velocity,

3. S/D—systolic/diastolic ratio,

4. RI-resistance index- $(\mathrm{S}-\mathrm{D}) / \mathrm{S}$,

5. $\mathrm{PI}-$ pulsatility index- $(\mathrm{S}-\mathrm{D}) / \mathrm{M}$,

6. CPR-PI of MCA/PI of umbilical artery.

\section{Doppler in Obstetrics}

1. Uteroplacental circulation-uterine artery,

2. Feto-placental circulation-umbilical artery,

3. Fetal circulation-middle cerebral artery, ductus venosus.

\section{Uterine Artery}

Uterine artery is a branch of anterior division of internal iliac artery.

\section{Uterine Artery Doppler}

Up to 16 weeks of gestation, an early diastolic notch is usually present in the uterine artery.

Abnormalities in uterine artery Doppler are the presence of early diastolic notch in the second trimester, RI more than 0.6 and PI more than 1.45.

Abnormal uterine artery Doppler is a predictor of preeclampsia and IUGR.

\section{Umbilical Artery [3]}

Abnormal waveforms of the umbilical arteries occur in case of occlusion arteries of tertiary villi due to thrombosis, fibrinoid necrosis, etc.

\section{Fetal Middle Cerebral Artery $[4,5]$}

Middle cerebral artery has the advantage of being highly reproducible, and hence, it is chosen for study. Fetal cerebral blood flow is controlled by an autoregulatory mechanism which responds to oxygen saturation. Reduction in oxygen saturation causes dilatation of the intracerebral vessels which leads to an increased diastolic blood flow to the brain. Doppler study is carried out just beyond the origin of MCA at the circle of Willis. 
Doppler study of the MCA is also useful in fetal anemia which is reflected in the fetal MCA by increase in the PSV which is greater than 1.5 times MOM.

\section{Cerebro-Placental Ratio}

It is the ratio of PI in the umbilical artery to the PI in the MCA. In normal fetuses, it is greater than 1, while in fetal hypoxia it is less than or equal to 1 .

\section{The Non-stress Test}

The following are the main components [6-9].

1. Baseline fetal heart rate,

2. Baseline variability of fetal heart rate,

3. Accelerations,

4. Decelerations.

\section{Baseline Fetal Heart Rate}

It is the average fetal heart rate in increments of 5 beats per minute for a minimum of 2 min during a 10-min segment.

Normal range: 110-160 beats per minute,

Tachycardia: More than 160 beats per minute,

Bradycardia: Less than 110 beats per minute.

\section{Baseline Abnormalities}

\section{Tachycardia}

Causes Stress, hypoxia, infections, etc.

\section{Bradycardia}
(a) Fetal hypoxemia.
(b) Local anesthetics,
(c) Partial cord compression.

\section{Baseline Variability}

It refers to fluctuations in the baseline FHR which are irregular in amplitude and frequency.

(a) Absent: undetectable amplitude,

(b) Minimal: amplitude 5 beats per minute,

(c) Moderate: amplitude between 6 and 25 beats per minute, (d) Marked: amplitude more than $25 \mathrm{bpm}$.

Changes in Baseline Variability
(A) Fetal hypoxia,
(B) Fetal acidosis,
(C) Prematurity,
(D) Fetal sleep.

\section{Accelerations}

A visually apparent abrupt increase (onset to peak in less than $30 \mathrm{~s}$ ) in the fetal heart rate. Causes: fetal movement, uterine contractions, fetal stimulation [10, 11].

\section{Deceleration}

These are decreases in the fetal heart rate which go at least 15 beats below the baseline and last at least $15 \mathrm{~s}$.

\section{Early Deceleration}

Visually apparent usually symmetrical gradual decrease and return of the FHR associated with the uterine contraction.

Causes Head compression.

\section{Late Deceleration}

Usually symmetrical gradual decrease and return of the FHR associated with the uterine contraction.

Intrauterine Causes Placental insufficiency.

\section{Variable Deceleration}

Visually apparent abrupt decrease in FHR which may or may not be related to contractions and vary in onset in depth and duration.

\section{Causes}

1. Short or Long cord,

2. Oligohydramnios,

Sinusoidal Pattern Visually apparent, smooth, sine wavelike undulating pattern seen in fetal anemia. 


\section{Categorization [12]}

\begin{tabular}{|c|c|c|c|c|}
\hline Feature & $\begin{array}{l}\text { Baseline } \\
\text { (beats per } \\
\text { minute }\end{array}$ & Variability & Decelerations & Accelerations \\
\hline Reassuring & $110-160$ & $\geq 5$ & None & Present \\
\hline \multirow[t]{2}{*}{$\begin{array}{l}\text { Non- } \\
\quad \text { reassuring }\end{array}$} & 100-109 & $\begin{array}{l}<5 \text { for } \\
\quad 40-90 \mathrm{~min}\end{array}$ & $\begin{array}{l}\text { Typical variable } \\
\text { decelerations } \\
\text { with over } \\
50 \% \text { of } \\
\text { contractions } \\
\text { occurring for } \\
\text { over } 90 \mathrm{~min}\end{array}$ & \multirow[t]{5}{*}{$\begin{array}{l}\text { The absence of } \\
\text { accelerations } \\
\text { with } \\
\text { otherwise } \\
\text { normal trace } \\
\text { is of } \\
\text { uncertain } \\
\text { significance }\end{array}$} \\
\hline & $161-180$ & & $\begin{array}{l}\text { Single prolonged } \\
\text { deceleration } \\
\text { for up to } \\
3 \mathrm{~min}\end{array}$ & \\
\hline \multirow[t]{3}{*}{ Abnormal } & $<100$ & \multirow{3}{*}{$\begin{array}{l}<5 \text { for } \\
\quad>90 \mathrm{~min}\end{array}$} & \multirow[b]{2}{*}{$\begin{array}{l}\text { Either atypical } \\
\quad \text { variable } \\
\text { decelerations } \\
\text { with over } \\
50 \% \text { of } \\
\text { contractions } \\
\text { or late } \\
\text { decelerations, } \\
\text { both for over } \\
30 \text { min }\end{array}$} & \\
\hline & $>180$ & & & \\
\hline & $\begin{array}{c}\text { Sinusoidal } \\
\text { pattern } \\
\geq 10 \mathrm{~min}\end{array}$ & & $\begin{array}{l}\text { Single prolonged } \\
\text { deceleration } \\
\text { for more than } \\
3 \mathrm{~min}\end{array}$ & \\
\hline
\end{tabular}

\section{Materials and Methods}

\section{Study Design}

Prospective study.

\section{Duration of Study}

One year.

\section{Cases}

The study included two hundred high-risk pregnancies attending antenatal clinic at ISO KGH who satisfied the inclusion criteria.

\section{Inclusion Criteria}

Women with gestational age greater than 34 weeks with risk factors like anemia, GDM.

\section{Exclusion Criteria}

Pregnancies with gestational age $<34$ weeks, postdated pregnancies, etc.

Complete history taking and general physical and systemic examination and investigations were done for all the patients. They were followed up till delivery, and the outcome was studied in detail. NST was repeated biweekly, and Doppler was performed once in 15 days or more frequently based on the findings.

\section{Follow-Up}

Gestational age at delivery, mode of delivery, APGAR, birth weight, NICU admission, etc., were the outcomes analyzed.

Results were tabulated, analyzed statistically and evaluated.

Patients were categorized into four groups as follows:

Group I Doppler normal and NST reactive,

Group IIA Doppler normal but NST non-reactive,

Group IIB Doppler abnormal but NST reactive.

Group III Doppler abnormal and NST non-reactive.

\section{Results}

Totally, $35 \%$ cases had hypertensive disorders in pregnancy.

\begin{tabular}{llllllllll}
\hline $\begin{array}{l}\text { Within } \\
\text { the } \\
\text { group }\end{array}$ & $\begin{array}{l}\text { Group } \\
\text { I }\end{array}$ & $\%$ & $\begin{array}{l}\text { Group } \\
\text { IIA }\end{array}$ & $\begin{array}{l}\text { Group } \\
\text { IIB }\end{array}$ & $\begin{array}{l}\text { Group } \\
\text { III }\end{array}$ & \\
\hline No & 86 & 68.80 & 12 & 41.38 & 6 & 60 & 25 & 69.44 \\
Yes & 39 & 31.20 & 17 & 58.62 & 4 & 40 & 11 & 30.56 \\
Total & 125 & 100 & 29 & 100 & 10 & 100 & 36 & 100 \\
\hline
\end{tabular}

\begin{tabular}{lrlrl}
\hline Among the groups & No & $\%$ in "no" & Yes & $\%$ in “yes" \\
\hline Group I & 86 & 66.67 & 39 & 54.93 \\
Group IIA & 12 & 9.30 & 17 & 23.94 \\
Group IIB & 6 & 4.65 & 4 & 5.63 \\
Group III & 25 & 19.38 & 11 & 15.49 \\
Total & 129 & 100 & 71 & 100 \\
\hline
\end{tabular}


The incidence of GDM was $17 \%$

\begin{tabular}{lrlrl}
\hline Among the groups & No & \% in "no" & Yes & $\%$ in “yes" \\
\hline Group I & 105 & 63.25 & 20 & 58.82 \\
Group IIA & 23 & 13.86 & 6 & 17.65 \\
Group IIB & 9 & 5.42 & 1 & 2.94 \\
Group III & 29 & 17.47 & 7 & 20.59 \\
Total & 166 & 100 & 34 & 100 \\
\hline
\end{tabular}

IUGR

\begin{tabular}{lrlrlllll}
\hline $\begin{array}{l}\text { Within } \\
\text { the } \\
\text { group }\end{array}$ & $\begin{array}{l}\text { Group } \\
\text { I }\end{array}$ & $\%$ & $\begin{array}{l}\text { Group } \\
\text { IIA }\end{array}$ & $\%$ & $\begin{array}{l}\text { Group } \\
\text { IIB }\end{array}$ & $\begin{array}{l}\text { Group } \\
\text { III }\end{array}$ & $\%$ \\
\hline No & 123 & 98.40 & 28 & 96.55 & 9 & 90 & 25 & 69.44 \\
Yes & 2 & 1.60 & 1 & 3.45 & 1 & 10 & 11 & 30.56 \\
Total & 125 & 100 & 29 & 100 & 10 & 100 & 36 & 100 \\
\hline
\end{tabular}

\begin{tabular}{lrlcl}
\hline Among the groups & No & $\%$ in “no" & Yes & $\%$ in “yes” \\
\hline Group I & 123 & 66.49 & 2 & 13.33 \\
Group IIA & 28 & 15.14 & 1 & 6.67 \\
Group IIB & 9 & 4.86 & 1 & 6.67 \\
Group III & 25 & 13.51 & 11 & 73.33 \\
Total & 185 & 100 & 15 & 100 \\
\hline$P$
\end{tabular}

$P$ value $<0.001$

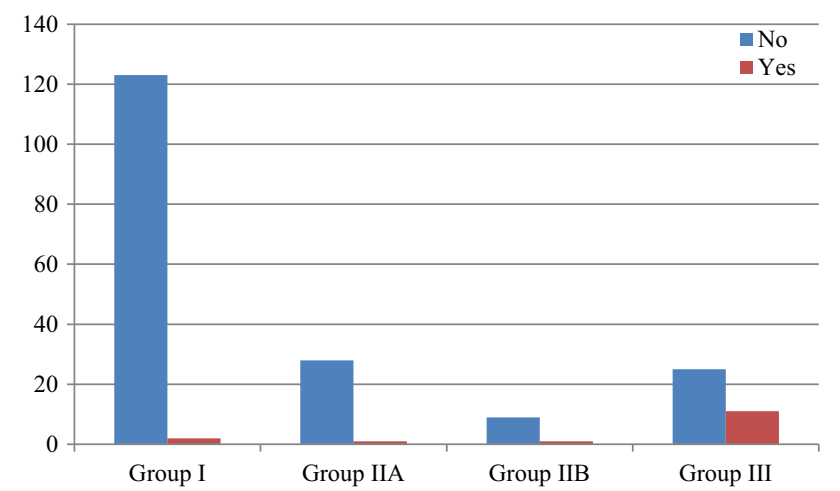

Totally, there were 15 cases of IUGR, and $74 \%$ of them belonged to Group III. $P$ value is $<0.001$ and hence highly significant.

LIQUOR

\begin{tabular}{lrlcllllll}
\hline $\begin{array}{l}\text { Within the } \\
\text { group }\end{array}$ & $\begin{array}{l}\text { Group } \\
\text { I }\end{array}$ & $\begin{array}{l}\text { Group } \\
\text { IIA }\end{array}$ & $\begin{array}{l}\text { Group } \\
\text { IIB }\end{array}$ & $\begin{array}{l}\text { Group } \\
\text { III }\end{array}$ \\
\hline Normal & 117 & 93.60 & 23 & 79.31 & 8 & 80 & 25 & 69.44 \\
Oligohydramnios & 6 & 4.80 & 6 & 20.69 & 2 & 20 & 11 & 30.56 \\
Polyhydramnios & 2 & 1.60 & 0 & 0.00 & 0 & 0 & 0 & 0.00 \\
Total & 125 & 100 & 29 & 100 & 10 & 100 & 36 & 100 \\
\hline
\end{tabular}

\begin{tabular}{lrlllll}
\hline $\begin{array}{l}\text { Among } \\
\text { the } \\
\text { groups }\end{array}$ & Normal & $\begin{array}{l}\% \text { in } \\
\text { normal }\end{array}$ & $\begin{array}{l}\text { Oligo- } \\
\text { hydramnios }\end{array}$ & $\begin{array}{l}\% \text { in } \\
\text { oligohyd. }\end{array}$ & $\begin{array}{l}\text { Poly- } \\
\text { hydramnios }\end{array}$ & $\begin{array}{l}\% \text { in } \\
\text { poly } \\
\text { hyd. }\end{array}$ \\
\hline Group I & 117 & 67.63 & 6 & 24.00 & 2 & 100.00 \\
Group IIA & 29 & 13.29 & 6 & 24.00 & 0 & 0.00 \\
Group IIB & 8 & 4.62 & 2 & 8.00 & 0 & 0.00 \\
Group III & 25 & 14.45 & 11 & 44.00 & 0 & 0.00 \\
Total & 173 & 100 & 25 & 100 & 2 & 100 \\
\hline$P$ value 0.002 & & & & &
\end{tabular}

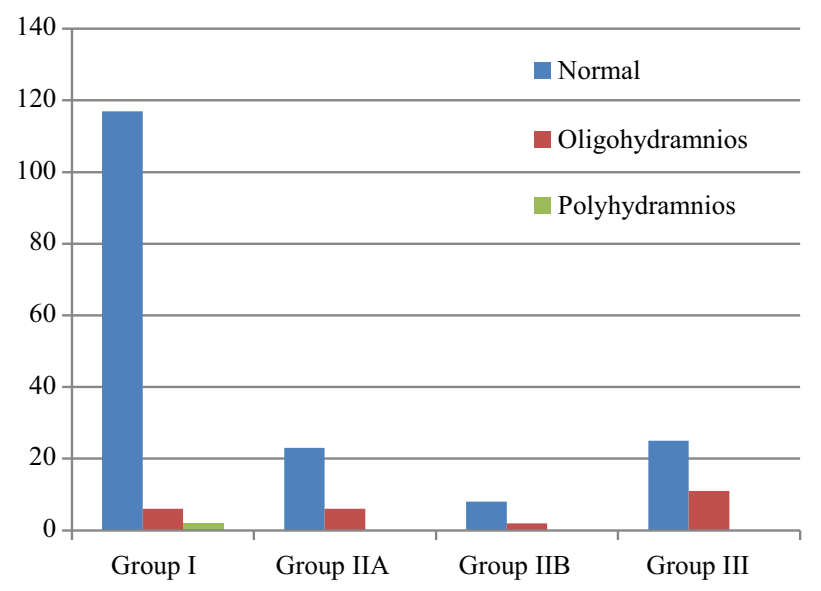

Of the 25 cases with oligohydramnios, 44 and $8 \%$, respectively, fell into Groups III and IIB which was significant. $P$ value is .002 and hence highly significant.

MCA

\begin{tabular}{lcl}
\hline Description & Frequency & Percent \\
\hline Normal & 154 & 77 \\
Abnormal & 46 & 23 \\
\hline
\end{tabular}

Mode of delivery

\begin{tabular}{lclrlll}
\hline $\begin{array}{l}\text { Among } \\
\text { the } \\
\text { groups }\end{array}$ & $\begin{array}{l}\text { Vaginal } \\
\text { dely. }\end{array}$ & $\begin{array}{l}\text { \% in } \\
\text { vaginal } \\
\text { dely. }\end{array}$ & $\begin{array}{l}\text { CS for } \\
\text { fetal } \\
\text { distress }\end{array}$ & $\begin{array}{l}\text { \% in CS } \\
\text { for fetal } \\
\text { distress }\end{array}$ & $\begin{array}{l}\text { CS } \\
\text { for } \\
\text { others }\end{array}$ & $\begin{array}{l}\text { \% in } \\
\text { CS for } \\
\text { others }\end{array}$ \\
\hline Group I & 89 & 90.82 & 1 & 1.49 & 35 & 100.00 \\
Group IIA & 1 & 1.02 & 28 & 41.79 & 0 & 0.00 \\
Group IIB & 3 & 3.06 & 7 & 10.45 & 0 & 0.00 \\
Group III & 5 & 5.10 & 31 & 46.27 & 0 & 0.00 \\
Total & 98 & 100 & 67 & 100 & 35 & 100 \\
\hline
\end{tabular}

$P$ value $<0.001$ 
In Group IIA, in about $97 \%$ cases cesarean section was done for fetal distress. In Group IIB where Doppler was abnormal but still NST was reactive, successful induction was done in $30 \%$ of cases. In Group III when Doppler and NST were abnormal, $90 \%$ of the cases ended up in cesarean section.

Birth weight

\begin{tabular}{lrlrlll}
\hline $\begin{array}{l}\text { Among the } \\
\text { groups }\end{array}$ & $>2.5$ & $\begin{array}{l}\% \text { in } \\
>2.5\end{array}$ & $\begin{array}{r}2-2.5 \% \text { in } \\
2-2.5\end{array}$ & $\begin{array}{l}<2.5 \\
\% \text { in } \\
<2.5\end{array}$ \\
\hline Group I & 122 & 80.26 & 3 & 7.69 & 0 & 0.00 \\
Group IIA & 20 & 13.16 & 9 & 23.08 & 0 & 0.00 \\
Group IIB & 4 & 2.63 & 4 & 10.26 & 2 & 22.22 \\
Group III & 6 & 3.95 & 23 & 58.97 & 7 & 77.78 \\
Total & 152 & 100 & 39 & 100 & 9 & 100 \\
\hline
\end{tabular}

$P$ value $<0.001$

In Group III, $82 \%$ cases had low birth weight. $P$ value is $<0.001$ and hence highly significant.

NICU admission

\begin{tabular}{lllll}
\hline Among the groups & No & \% in "no" & Yes & $\%$ in “yes" \\
\hline Group I & 123 & 84.83 & 2 & 3.64 \\
Group IIA & 20 & 13.79 & 9 & 16.36 \\
Group IIB & 1 & 0.69 & 9 & 16.36 \\
Group III & 1 & 0.69 & 35 & 63.64 \\
Total & 145 & 100 & 55 & 100 \\
\hline
\end{tabular}

$P$ value $<0.001$

Among the 55 cases admitted, only 11 of them were from the Doppler normal group. In Group IIA where NST alone was non-reactive, only 9 cases were admitted among the 29 . In Groups IIB and III, 90 and $98 \%$ cases, respectively, were admitted. $P$ value is $<0.001$ and hence highly significant.

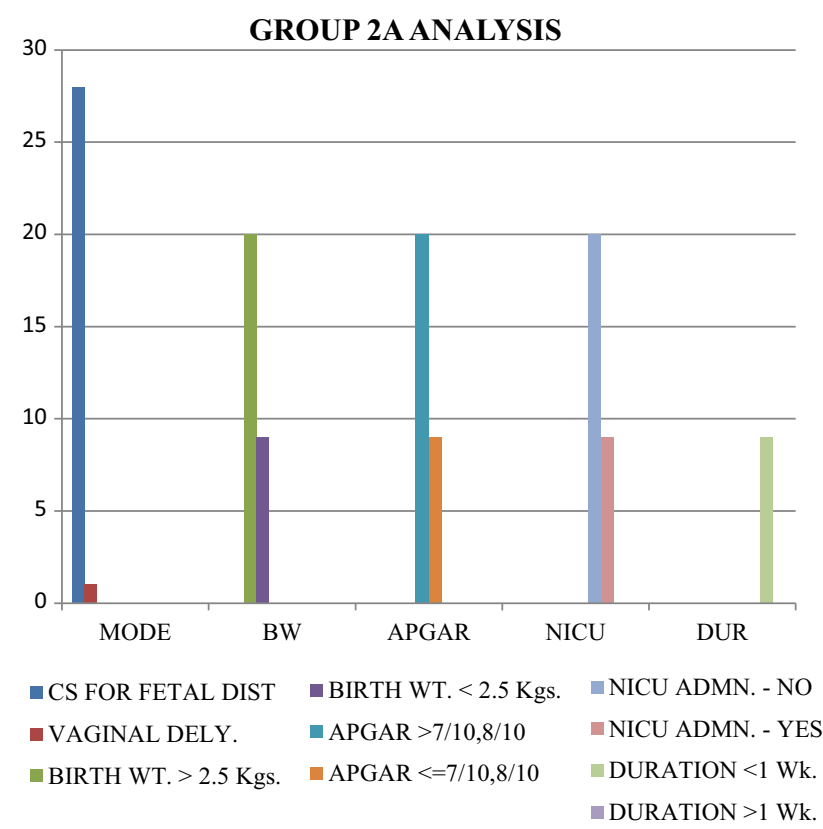

There was a high incidence of cesarean section in this group. But perinatal outcome was not adverse.

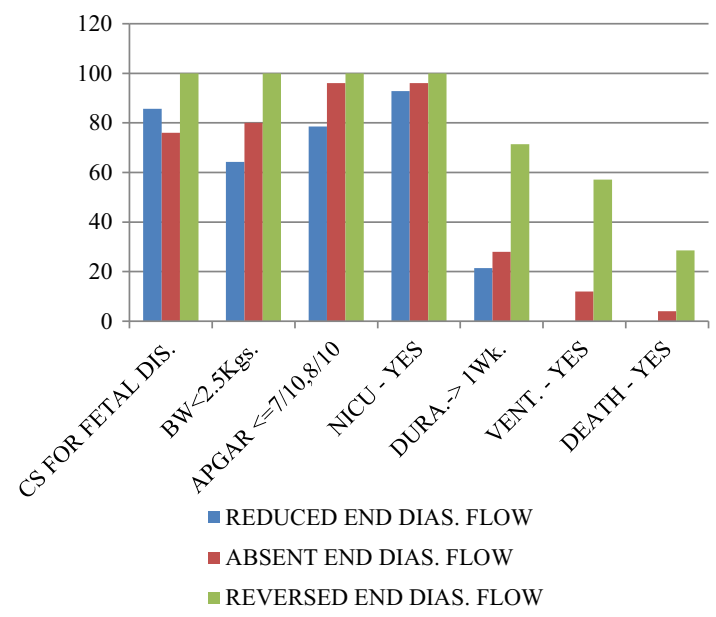

Comparison of adverse outcome among different Doppler abnormalities showed a higher incidence of adverse perinatal outcome with the worsening of Doppler changes.

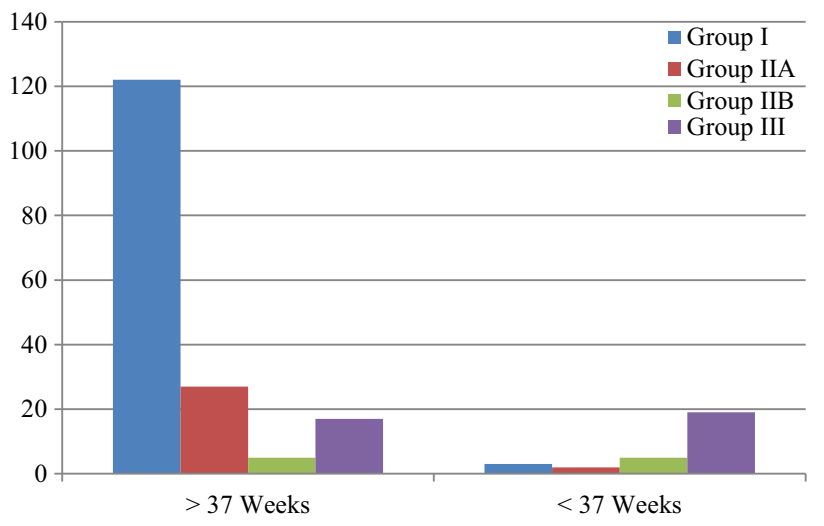

In Groups I and IIA, where Doppler was normal, 98 and $94 \%$ cases, respectively, were terminated after 37 weeks. In Group IIB where Doppler was abnormal, but NST was still reactive, $50 \%$ of the cases were delivered after 37 weeks. But in Group III where both were abnormal, nearly $53 \%$ were terminated preterm. Overall, more than $80 \%$ of preterm deliveries belonged to Doppler abnormal group among which $65 \%$ belonged to Group III where NST was also non-reactive. $P$ value is $<0.001$ and hence highly significant. 


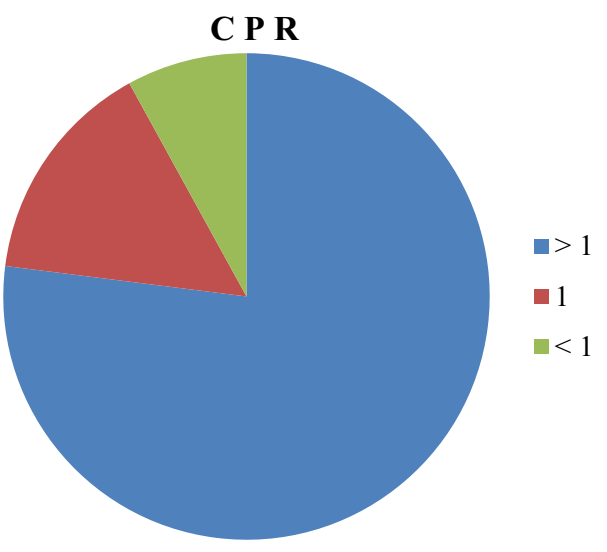

\begin{tabular}{lcc}
\hline Description & Frequency & Percent \\
\hline$>1$ & 154 & 77 \\
1 & 30 & 15 \\
$<1$ & 16 & 8 \\
\hline
\end{tabular}

\section{Discussion}

This is a prospective study to analyze the efficacy of Doppler and the non-stress test in predicting perinatal outcome in high-risk pregnancies and find out the superior option.

When both Doppler and non-stress test were normal, most of the pregnancies were carried successfully till term. Likewise, when Doppler was normal but NST was nonreactive, there were only $7 \%$ of deliveries before term. But on the other hand when Doppler and NST both were abnormal, nearly $53 \%$ cases were terminated before term which indicates that adverse outcome is more common in this group. In the Group IIB where Doppler was abnormal, but still NST remained reactive, it was possible to carry $50 \%$ pregnancies till term.

In these cases after trying measures to resolve the pattern, NST was repeated for a period of $90 \mathrm{~min}$, but still there was no improvement and the patterns remained the same. Hence, these pregnancies were terminated.

\section{CPR Versus APGAR, Birth Weight and NICU Admission}

When CPR was greater than 1 (154 cases), most of these babies (93\%) had good APGAR scores. When CPR was less than or equal to 1 , those babies had low APGAR scores.
When CPR was greater than 1 (152 cases), $93 \%$ of the babies had normal birth weight. When it was less than or equal to 1 , most of the babies had low birth weight (76 and $80 \%$, respectively).

Similarly, when CPR was less than or equal to 1 , most of the babies required NICU admission.

\section{Risk Factors}

Among the total 15 cases of IUGR, 11 cases belonged to Group III, indicating a higher association with abnormal Doppler and abnormal NST.

\section{Birth Weight}

Doppler abnormality was associated with a higher incidence of low-birth-weight babies. In Group I, there were only $2 \%$ cases with low birth weight. In Group IIA, where Doppler was normal about $70 \%$ babies had normal weight. This indicates good correlation between normal Doppler findings and the growth of the fetus. Coming to Group IIB, out of the 10 cases, 6 cases had low-birth-weight babies. In these cases, NST was still reactive and these babies had better outcome though they were admitted in NICU when compared to the Group III cases where NST was also nonreactive. In this group (both abnormal), about $80 \%$ babies had low birth weight and most of them were admitted in NICU with $36 \%$ cases having a longer duration of stay. Considering NST as a test of well-being when it is reactive, surely it indicates a better prognosis.

\section{APGAR}

Among the 29 cases in Group IIA, where decision was taken based on non-reactive NST, only 9 cases had low APGAR which proves the false positivity of NST. In Group IIB, there were 7 cases with low APGAR. The reason behind this though the NST was reactive, could have been the fact that these fetuses were already compromised (had abnormal Doppler findings) and could have faced an acute insult during the process of labor. Anyway these babies had better outcome when compared to Group III babies of which $98 \%$ had low APGAR.

\section{Ventilator Support}

When both Doppler and NST were abnormal, six of the babies needed ventilator's support and three of them died. All three of the babies were born to mothers with severe preeclampsia. These patients had already developed irreversible changes in Doppler when they had their first visit to our hospital. 


\section{Conclusion}

The main aim of this study was to use the time-tested methods of fetal surveillance, the Doppler velocimetry and non-stress test to precisely predict the perinatal outcome in high-risk pregnancies and find out which is superior.

Not all high-risk pregnancies with abnormal Doppler alone are indications for immediate termination. Those with abnormal Doppler with reactive NST could be successfully monitored and can be prolonged so that the little time period available can be utilized for steroid prophylaxis and planning the mode of delivery rather than an immediate cesarean section.

On the contrary, a non-reactive NST with a normal Doppler study need not necessarily mean an adverse outcome. Considering the high false-positive rate of NST, it is better to look beyond and take a wise decision to avoid unnecessary cesarean sections.

Also it is found that an abnormal Doppler with a nonreactive NST is definitely associated with an adverse perinatal outcome than when only one of the above was abnormal. The incidence of premature induction, cesarean section for fetal distress, low APGAR, NICU admissions and need for ventilation were more in cases where both these tests were abnormal. Hence by combining the two, and acting appropriately, the incidence of adverse perinatal outcome may be reduced.

In pregnancies with multiple high-risk conditions, it is recommended to initiate testing as early as $26-28$ weeks of gestation.

Initiation of testing at 32-34 weeks of gestation is considered appropriate for pregnancies with increased risk of adverse outcome. A reassuring test should be repeated weekly or, depending on the test used and the presence of certain high-risk conditions, twice weekly until delivery.

Hence, no single test result should be considered for decision making in case of high-risk pregnancy because each test reflects different aspects of maternal and fetal pathophysiology. It is advisable to repeat the test and combine with other modes of fetal surveillance before decision making to improve the perinatal outcome and for better prediction of adverse events.
Funding This study was funded by self.

\section{Compliance with Ethical Standards}

Conflict of interest Authors have no conflicts of interest.

Ethical Approval Humans were involved. All procedures performed in studies involving human participants were in accordance with the ethical standards of the institutional and/or national research committee and with comparable ethical standards.

Informed Consent Informed consent was obtained from all individual participants included in the study.

\section{References}

1. Maulik D, Yarlagadda P, Downing G. Doppler velocimetry in obstetrics. Obstet Gynecol Clin N Am. 1990;17:163-86.

2. Maulik D. Basic principles of Doppler ultrasound as applied in obstetrics. Clin Obstet Gynecol. 1989;32:628-44.

3. Giles WB, Trudinger BJ, Baird PJ. Fetal umbilical artery flow velocity waveforms and placental resistance: pathological correlation. Br J Obstet Gynaecol. 1985;92:31-8.

4. Vyas S, Nicolaides $\mathrm{KH}$, Bower S, et al. Middle cerebral artery flow velocity waveforms in fetal hypoxaemia. $\mathrm{Br} \mathrm{J}$ Obstet Gynaecol. 1990;97:797-803.

5. Burns PN. Doppler flow estimations in the fetal and maternal circulations: principles, techniques and some limitations. In: Maulik D, McNellis D, editors. Doppler ultrasound measurement of maternal-fetal hemodynamics. Ithaca: Perinatology Press; 1987. p. 43-78.

6. Krebs HB, Petres RE. Clinical application of a scoring system for evaluation of antepartum fetal heart rate monitoring. Am J Obstet Gynecol. 1978;130:765.

7. Lyons ER, Bylsma-Howell M, Siamsi S, et al. A scoring system for nonstressed antepartum fetal heart rate monitoring. Am J Obstet Gynecol. 1979;133:242.

8. Devoe LD, Yanowitch G, Azor H. The application of multipleparameter scoring to antepartum fetal heart rate testing. J Reprod Med. 1981;26:250.

9. Pearson JF, Weayer JB. A six-point scoring system for antenatal cardiotocographs. Br J Obstet Gynaecol. 1978;85:321.

10. Nathanielsz PW, Bailey A, Poore ER, et al. The relationship between myometrial activity and sleep state and breathing in fetal sheep throughout the last third of gestation. Am J Obstet Gynecol. 1980;138:653.

11. Powell OH, Melville A, MacKenna JL. Fetal heart rate acceleration in labor: excellent prognostic indicator. Am J Obstet Gynecol. 1979;134:36.

12. Sharbaf FR, Amjadi N, Alavi A, et al. Normal and indeterminate pattern of fetal cardiotocography in admission test and pregnancy outcome. J Obstet Gynaecol Res. 2014;40(3):694-9. 